\title{
ÉTICA GLOBAL: CONSIDERACIONES SOBRE SU RELEVANCIA EN LOS ESTUDIOS INTERNACIONALES
}

\author{
Global ethics and its relevance in \\ international studies
}

Fernando Lolas Stepke*

\section{Resumen}

Se ilustra el concepto de ética global tomando como ejemplo la noción de salud global. Las implicaciones de un concepto global superan las consideraciones geopolíticas y en este texto se las identifica con el cometido transdisciplinario de una reflexión que considera diversas perspectivas metódicas y filosóficas. Las sugerencias brindadas por el ejemplo de la salud internacional y global se presentan como estímulo para la aplicación del concepto a otras áreas de interés en el campo de los estudios internacionales.

Palabras Clave: ética global, bioética, salud global, salud internacional, transdisciplinariedad

\section{Abstract}

The concept of global ethics is illustrated base don the example provided by global health. The implications of a global concept go beyond geopolitical considerations and this paper identifies them with the transdisci-

Académico, Instituto de Estudios Internacionales y Centro Interdisciplinario de Estudios en Bioética, Universidad de Chile. flolas@u.uchile.cl.

Recibido el 7 de diciembre; aceptado el 21 de enero de 2013. 
plinary task of a reflection that incorporates different methodical and philosophical perspectives. Suggestions offered by the example of global and international health are presented as a stimulus for the application of the concept to other areas of interest in the field of international studies.

KeYwORDs: global ethics, bioethics, global health, International health, transdisciplinariness 
FERNANDO Lolas • Ética global: consideraciones sobre su relavancia...

\section{LOS VALORES NO CONOCEN FRONTERAS}

Bajo cualquier concepto de globalización, es evidente que si bien las fronteras del estado nacional impiden la difusión universal del conocimiento estratégico y segregan a las comunidades del mundo según variables socioeconómicas o identitarias, las consecuencias morales de cualquier decisión en las ciencias y la tecnología no conocen fronteras. Lo que acontece en los laboratorios de las Mecas de la tecnociencia puede ser materia de secreto por razones económicas o estratégicas. Pero sus efectos influyen en las decisiones de todo el mundo. Casi ningún centro de investigación en países científicamente limitados puede hoy aportar informaciones o construir conocimiento avanzado sobre genómica y clonación. No obstante, la comunidad internacional y las legislaciones nacionales han adoptado medidas para regular sus potenciales efectos y aplicaciones.

Sirva este ejemplo preliminar para justificar el campo temático de la ética global como una preocupación académica válida y relevante. En este breve texto ilustraremos algunas de sus implicaciones en base al ejemplo brindado por la salud humana y su mejora y promoción. Pero las conclusiones, esperamos, sobrepasan las limitaciones del ejemplo.

\section{LA SALUD Y LAS POLÍTICAS PÚBLICAS}

La Asamblea General de Naciones Unidas, en declaración oficial del 12 de diciembre de 2012, hace un llamado a considerar la salud y los temas relacionados con ella (sistemas sanitarios, infraestructura, transferencias entre investigación y aplicación) como un componente esencial en toda formulación de políticas públicas. Especialmente, señala la declaración, en lo que respecta a equidad y justicia, políticas públicas razonadas y razonables, desarrollo sustentable y sostenible.

El tema de la salud como componente de las relaciones internacionales, de la conformación de organismos supranacionales y de apoyo a un ambiente favorable a la implementación de estrategias para el desarrollo exige ser incorporado a los estudios sobre política y relaciones internacionales. No solamente por la crucial importancia que el sector salud adquiere en la inversión social. También, porque entre los determinantes sociales de la salud se debe contar la inestabilidad política, la amenaza terrorista, los controles de drogas ilícitas por parte de organismos fiscalizadores de fronteras y la convivencia general de las naciones. Los desastres económicos y naturales impactan el bienestar de los ciudadanos de todo el mundo. Puede decirse que sus consecuencias se globalizan tan rápido como las fluctuaciones de los mercados o los cambios de regímenes políticos. A su vez, el estado general de satisfacción 
y buena calidad de vida de las comunidades incide sobre su productividad, su aceptación o rechazo de políticas públicas y su inserción en la comunidad global de las naciones (Lolas, 1999).

Los esfuerzos en torno a la salud global suelen estudiarse bajo el concepto de salud internacional, reconociendo que en el actual estado de política mundial, siguen siendo protagonistas las naciones y los estados nacionales. La escasa participación de la sociedad civil puede explicarse por la baja en la representatividad de los gobernantes y la ausencia de canales adecuados de comunicación, incluso dentro de estados democráticos. La noción de la salud como un derecho que debe ser provisto por el Estado, con mayor o menor participación del mercado, convierte a la demanda por servicios en una inagotable fuente de frustraciones e inquietud, toda vez que las demandas por salud, como por educación y bienestar son infinitas y crecen al acelerado ritmo que impone la tecnificación de las innovaciones útiles.

\section{EL CONCEPTO DE SALUD}

\section{GLOBAL Y SUS IMPLICACIONES ÉTICAS}

El concepto de salud global tiene su origen en una forma especial de salud internacional: aquella que promovieron las potencias coloniales en los siglos XIX y XX con el fin de mantener hegemonía y asegurar recursos de los países en desventaja. No deja de ser interesante que muchas acciones filantrópicas hayan derivado de la conciencia de grupos en las economías dominantes que de ese modo aplacaban la conciencia colectiva indicando la preocupación por el bienestar de los dominados. En formas menos sutiles, la apropiación por parte de Estados Unidos del papel de salvador de vidas y bienestar en casos de epidemia. No es extraño a esta perspectiva el deseo de proteger el comercio, amenazado por malas condiciones de vida en México y las antiguas colonias españolas. Las cuarentenas y la necesaria limitación de la movilidad de personas y productos obligaban, cuando era necesario, a acciones ya no limitadas al campo de lo sanitario sino también al militar. La invasión de Veracruz durante una epidemia de cólera es un buen ejemplo. La instalación de consejerías y apoyos logísticos en diversos países del llamado Tercer Mundo, convenientemente formuladas como esfuerzos en pro de la salud internacional son otras formas soterradas de manifestar, por una parte, preocupaciones humanitarias, y por otra, mantener el control sobre las condiciones de los países dependientes. Un sugerente análisis de Kienzler y Pedersen (2012) propone examinar las semejanzas entre dominación militar y «tratamiento». No debe olvidarse que los esfuerzos civilizatorios de las potencias coloniales siempre aunaron, y aúnan hoy, la intervención militar manifiesta o encubierta y la «ayuda humanitaria», la "conversión a la verdadera fe» y el acceso a la cultura hegemónica. 
FERnANDo Lolas • Ética global: consideraciones sobre su relavancia...

La tensión norte-sur, analizada en esta perspectiva, es un asunto moral tanto como económico o político.

Sin embargo, el concepto de salud global supone extenderse más allá de esta dimensión geopolítica. La idea del estado nacional como garante de la salud y entidad capaz de entrar en diálogo con otras entidades semejantes pierde densidad si se considera un concepto más amplio. Salud global indica que la salud no solamente es asunto de sanidad o de tecnologías biomédicas. Incorpora de modo natural la existencia de otros discursos, complementarios pero esenciales, en la definición de salud. Por ejemplo, la perspectiva de las ciencias sociales, la cosmovisión de las poblaciones y comunidades y, aunque siempre repetido nunca comprendido, el concepto de diversidad cultural. Salud global es un sintagma que necesariamente supera afirmaciones ingenuas como "determinantes sociales» o «influencia de la pobreza» e incluso llamados a un valor denominado «equidad», que tiene un escurridizo sentido cuando se aplica a poblaciones pauperizadas, sometidas a conflictos bélicos o desastres naturales. Cualquier prejuicio valorativo puede dejarse fuera de la definición, toda vez que ya la misma noción de salud no es valóricamente neutral y hay muchos motivos para preferir la expresión «calidad de vida» en su lugar. Especialmente cuando se trata con poblaciones, queda en evidencia que la salud colectiva no es simplemente la suma de las saludes individuales sino un esfuerzo comunitario por generar instrumentos de análisis, conceptos y prácticas que tienen como sujeto de derechos y deberes la comunidad y no el individuo. Tal es, por otra parte, el sentido de la salud pública, que no se agota con las medidas de promoción y prevención sino incluye la necesaria interfaz con los esfuerzos de organismos privados y empresas. Global indica también en esta perspectiva la posibilidad de integrar Estado y mercado de manera armoniosa en la consecución de vidas saludables y satisfacciones para los ciudadanos (Lolas et al., 2007).

\section{LA ÉTICA GLOBAL COMO \\ COMETIDO TRANSDICIPLINARIO}

El término global, por ende, no alude solamentea la dimensión geográfica. Incluye una variedad de discursos, algunos más amplios que otros, y la necesaria integración o contrastación entre ellos. No es de extrañar que podamos asimilarlos a la idea de «allgemeineMedizin" con que Viktor von Weizsäcker trataba de formular sus atisbos y anticipaciones. Allgemein, que quiere decir general en sentido amplio, no significa en los escritos de la escuela de Heidelberg una forma de medicina que toma como punto de partida y estudio todas las dolencias (como en la expresión «médico general»). Significa una integralidad conceptual, metódica y moral que justifica pensar, por ejemplo, que la ética no es algo que deba serle impuesto a la medicina desde 
fuera (desde una reflexión filosófica, por ejemplo) sino una emanación propia y auténtica del oficio (Christian, 1997). En este concepto de una «medicina antropológica", a una salud global corresponde una ética global, concebida como interrelación de perspectivas .La fertilización cruzada de discursos (y por ende hablantes) distintos es lo que en sus primeros balbuceos trató de decir Potter cuando abogaba por una solidaridad biosférica y un respeto por todos los seres vivos, recapitulando sin saber las ideas de Fritz Jahr sobre el respeto a la vida en todas sus formas. Global es aquí transdisciplinar, un discurso híbrido que no puede contentarse con la admonición piadosa o la norma férrea sino surge del diálogo entre discursos, entre personas, entre grupos.

Englobando todo es posible que no se llegue a nada. Los esfuerzos universalistas, desde las religiones a la teoría de sistemas, terminan siendo construcciones vacías, pura forma sin contenido si no se previene la mantención del discurso de cada uno de los partícipes del diálogo en su originalidad y en su especificidad. El gran desafío no es, como suele pensarse, obtener más datos y más informaciones con aplicaciones productivas o útiles, sino diseñar formas en las cuales se genere conocimiento social. Aquel conocimiento que no es solamente información sino información organizada y estructurada en vistas de alguno de los muchos intereses y motivaciones que legítimamente existen en las sociedades. ¿Dónde está el conocimiento que perdimos en la información? se preguntaba T.S. Elliot hace ya décadas. ¿Dónde está la tarea de integrar no solamente las dos culturas de que hablaba C.P. Snow sino las múltiples culturas que surgen de las convicciones morales y de las emociones colectivas de los grupos humanos (nacionalismos, etnicismos, racismos, clasismos, etc.,)? Las culturas no son solamente construcciones cognitivas, también son amalgamas de deseos, expectativas e imágenes, propias y ajenas, que deben ser armonizadas.

La mayor dificultad estriba, como es natural, no en decir esto sino en llevarlo a la práctica. La respuesta habitual es hablar de educación, como si esta sola palabra, con su ascendiente mágico sobre las conciencias, traspasara el problema a un incierto futuro, aquel en el cual las nuevas generaciones, debidamente advertidas por las precedentes, no cometerán los yerros del unilateralismo valórico, ni llamarán dato a lo que es sólo creencia, ni lucharán por abstracciones como la patria, la clase social o el dios de sus ancestros. Es verdad que educando generaciones para la paz es posible esperar que en las conciencias se incubara la paz. Pero los tiempos y las circunstancias mutan, a despecho de los afanes de permanencia e inmortalidad que acometen, como un virus maligno, a quienes detentan poder. Pero he aquí la paradoja. No hay religión ni creencia que, debidamente usada, no sea motivo de abuso contra otros seres humanos. Digo debidamente usada, pues el proselitismo es de la esencia de toda poderosa motivación humana. Bastaría pensar en 
FERNANDO Lolas • Ética global: consideraciones sobre su relavancia...

las grandes religiones monoteístas, con su historia de crueldad y destrucción, o en los totalitarismos políticos del siglo $\mathrm{XX}$, cuya afinidad con el esquema religioso es innegable para percibir que una ética global (corolario y acompañante de salud global) debe ser sostenible en el tiempo y sustentable con razones y emociones. Aquí el concepto de globalidad adquiere una vertiente temporal que no debe confundirse con afán de inmortalidad. Debe tomarse como la búsqueda de aquellas invariantes perceptibles en el curso de la historia humana (tal vez no siempre de occidente) que autorizan a erigirlas como base de lo humano y derivar de allí la dignidad y la sacralidad de lo propiamente humano (Rowson et al., 2012).

\section{EL CONOCIMIENTO PARA LA}

\section{SALUD, TAREA UNIVERSAL DE}

\section{LAS COMUNIDADES}

Para el análisis de los sistemas de investigación en salud es necesario reconocer que constituyen un sistema híbrido. Compuesto, por una parte, por el sistema de salud con sus finalidades propias. Y por otra, por el sistema de investigación científico-tecnológica. Las racionalidades son diferentes. Las culturas epistémicas de sus practicantes no siempre son compatibles. La manifestación institucional de tales sistemas difiere en puntos clave. Por ejemplo, la dedicación al servicio universal del sistema de salud no equivale a la dedicación del sistema investigativo a generar certidumbres, a veces de naturaleza no directamente aplicable.

Pang y colaboradores (2003) identifican cuatro áreas en las cuales la investigación es relevante para el análisis de los sistemas de salud. Ellos se identifican con una función de supervisión y orientación, un estudio de la sostenibilidad y sustentabilidad financieras, la creación y mantención de recursos adecuados y la producción y el uso de los resultados de la investigación,.

No cabe dudar de que estas cuatro funciones de la investigación, especialmente la última, se ligan íntimamente a la contextura moral de los agentes que las practican. Así como hay personas inmorales, también puede decirse que hay Estados que no respetan, en su trayectoria histórica, el derecho de otros pueblos a acceder a los bienes civilizatorios respetando su diversidad y su dignidad.

\section{ÉTICA GLOBAL, MORAL LOCAL}

La globalización ha traído consigo varias comprobaciones. La primera, es que no se puede discutir de ética sin aludir al tema del poder. Suponemos, desde Francis Bacon, que el conocimiento es poder. Pero hoy sabemos que el poder modula el conocimiento. Incluso, puede decirse que lo crea si por conocimiento entendemos las certidumbres organizadas en torno a pruebas y demostraciones. La segunda comprobación, menos halagüeña, es que la globalización ha significado la 
imposición de un esquema local a la población global. Los valores occidentales están en la médula de las intervenciones, a veces bienintencionadas, con que se tratan temas propios de las culturas en las que se imponen. Nunca el juicio moral puede ignorar las circunstancias en que se enjuicia y cómo se enjuicia. Toda moral es local, si bien la ética -como reflexión razonada y razonable sobre la moral- puede aspirar a universalidad procedimental. De allí que la "glocalización» más que la globalización sea lo adecuado para avanzar en la construcción de una ética global.

Si aquí hemos ilustrado las perspectivas de una ética global con el ejemplo de la salud ha sido simplemente porque éste brinda una justificación intuitivamente válida para el esfuerzo de análisis, construcción y reflexión. Ciertamente, la gobernabilidad política, la institucionalidad, la educación y la diplomacia son campos en los cuales la noción de una ética global, desarrollada con suficiente generalidad y con adecuada relevancia local, puede ser tarea relevante.

\section{BiBLIOGRAFÍA}

CHRISTIAN, P. (1997) Medicina Antropológica (traducción, prólogo y notas de F. Lolas). Editorial Universitaria, Santiago de Chile

KIENZLER, H. y D. PEDERSEN 2012) Strange but common bedfellows: The relationship between humanitarians and the military in developing psychosocial interventions for civilian populations affected by armed conflict. Transcultural Psychiatry 49:492-518. LOLAS, F. (1999) La bioética en el contexto de los programas globales de salud. Revista Panamericana de Salud Pública (Washington) 6(1): 65-68.

LOLAS, F., D. K. MARTIN y A. QUEZADA, (Eds.) (2007) Prioridades en salud y salud intercultural. Centro Interdisciplinario de Estudios en Bioética, Universidad de Chile, Santiago (disponible en www.bioetica. uchile.cl)

PANG, T., R. SADANA, S. HANNEY, Z. BHUTTA, A. HYDER y J. SIMON. (2003) Knowledge for better health- a conceptual framework and foundation for health research systems. Bulletin of the World Health Organization 81:815-820.

ROWSON, M., C. WILLOTT, R. HUGHES y A. MAINI, et al. (2012) Conceptualising global health: theoretical issues and their relevance for teaching. Globalization and Health 8:36 (www.globalizationandhealth.com/content/8/1/36) 